DOI: https://doi.org/10.3126/njdrs.v17i0.34946

\title{
Contribution of Skill Test in Employment among Short Term Vocational Training Graduates
}

\author{
Bhanu Pandit* and Rajan Binayek Pasa, PhD** \\ *Monitoring and Evaluation Manager, EF- HELVETAS Swiss Intercooperation \\ Bakhundole, Lalitpur, GPO Box: 688, Kathmandu, Nepal \\ ** Lecturer at Central Department of Rural Development \\ Email for correspondence: bhanu.pandit@helvetas.org and rajan.pasa@cdrd.tu.edu.np
}

\begin{abstract}
This study analyzed contribution of vocational skills tests to the employment of trained graduates in different stages. In doing so, specialized survey was conducted with 305 graduates who received the skill training from private training institutes and attended the level-one skill test of NSTB. The results showed that skill testing system contributed to the employment of graduates specifically by accessing employment opportunities (pre-employment stage), increasing work performance (during-employment stage) and further job prosperity (post-employment). The segregation of the overall results showed that most of the graduates perceived that skill test contributed to all the employment stages.Men and women are equally benefitted with the skill tests to their employment. Similarly, youths from all age groups, all ethnic groups and all educational backgrounds were benefited in a similar manner from the skills test. However, it mattered whether a graduate was married or not, and which geographical area the graduate came from. As an implication, considering the contribution of the skill tests, the investment in skill tests in each of the vocational training is considered valuable and useful not only for the domestic workers including the migrants and returnees. Similarly, skills gained in the form of prior learning through informal and non-formal means can be tested, certified and recognized. Moreover, why the contribution of the skill tests varied according to the graduates' marital status and geographic origin, a finding of the study, remains an area for further research.
\end{abstract}

Key words: Capacity building, good governance, human development, political economy

\section{Background}

The contributions of skilled human resources are very crucial for economic prosperity. Vocational education is one of the vital means to produce skilled human resources that benefit equally to individuals, societal and the nation (Psacharopoulos \& Woodhall, 1997). Vocational education and training can make a significant contribution to human capital formation to serve the labor market demand. The vocational training, as it is known today, represents the combination of practical learning in workshops and theoretical subjects in class room settings (Schaack \& Tippelt, 2000).

In the Nepalese context, Council for Technical Education and Vocational Training (CTEVT) which was established in 1989 is regarded as an apex institute in the TVET sector. It was established 
under the Education Act, 1989 which was amended in 1993. The major responsibility of this institute is to prepare skilled human resources as per the demand of the labor market (CTEVT, 2005). The CTEVT, with its five years' Strategy Plan (2014-2018), is responsible to put the Ministry's policy into action. It aims at a TVET system which is market oriented, efficient, relevant and equitable (CTEVT, 2012). CTEVT has eleven divisions, and the National Skills Testing Board (NSTB) takes responsibility to conduct skill test. The skill test is being conducted at central as well as zonal level technical schools of the country (CTEVT, 2012). Skill test is one of the vital components of vocational education and training that tries to keep abreast with the labor market trends and provides opportunities to many skilled youths. A skill test is the test based on defined occupational skill standard that should be performed by every individual to obtain the national skill certificate after meeting the requirements of a trade or occupation (NSTB, 2012 as cited in Pasa, 2015).

It can be seen that the different kinds of vocational skills can be acquired through multiple ways. Therefore, the skill testing system for short term vocations should give the opportunities to all kinds of people acquiring skills form any means like formal, non-formal and informal. Thus, such kind of skill testing system should be accessible to skills people from the local to central level. Principally, skill testing system in Nepal gives emphasis to three different target groups: pass outs graduates of vocational education and skill development training, who are in transition to their work, experienced workers who lack official certification, and workers at the end of on-the-job training duration and seeking an additional national level certification (NSTB, 2012).

In the Nepalese context, the young people are comparatively high in number and are growing very rapidly. The size of such young population is estimated to be much bigger over the next few years. Thus, it can be supposed that the demand for skills training and its certification among the youths is increasing. However, due to poor provision and accessibility of the skill testing system for vocational trainings, most of the youths are still working without skill test certification (Kafle, 2007). In Nepal, more than half (54\%) of the population comprises productive age group i.e. 15-59 years. The adult (15 years and above) literacy rate for both male and female is 56.5 percent (Nepal Living Standard Survey [NLSS], 2016). Those huge masses of illiterate productive age group population have some certain types of vocational skill from informal and non-formal means. But they often encounter various problems, which include lack of awareness and knowledge on short term vocational skill training and skill testing system. These problems are often deteriorated by social and economic factors such as lack of confidence, poverty, poor skills for employability, lower access to resources etc. Many of these problems not only affect the physical and mental health of the youths but also their long-term emotional, economic and social well-being. It is important to recognize that socio-economic problems of common youths, particularly from rural areas, are the results of unemployment. To address such a vulnerable situation, it is essential to provide them an access to vocational skills training and certification so that unemployed youths can create their skill base and get better opportunities for employment (Sharma, 1998). The current employment market demands graduates having appropriate occupational skills and competencies that can be applicable to a wide range of employment situations. It is also proved by some of the previous studies by indicating the need of a range of skills, abilities and proficiencies (Bajracharya, 2010 as cited in Pasa, 2015). 
In this background, it is clearer that some of the government initiatives and foreign aids have invested in the school dropouts with the aims to provide occupational skill training to them and facilitate their entry to the gainful employment. Apart from the government initiatives, more than eleven donors are supporting to enroll about 40,000 youths every year in vocational skill training (CTEVT, 2011). In most of these interventions, skill test of the trained graduates is a mandatory provision. Therefore, conducting research for examining the contribution of the skill test to the employment of vocational skills training graduates is inevitable. Thus, the primary concern of this study is to analyze the contribution of the vocational skill testing system (i.e. level-one skill test ${ }^{1}$ ) to the employment of trained graduates or youths in personal and external levels. The definition of youth in this research has been made on the basis of National Youth Policy 2010 which comprises the 'women, men and third gender' persons aged 16-40 years old. Likewise, the personal traits are encouragement to apply for jobs, increase level of confidence, increase efficiency, increase self-awareness in safety and security and in decent work, self-recognition, purchasing power and living standard. Similarly, external traits on the other hands are increased job options, trust among the employers, recognition by other co-workers, level of income, increased career prospects, team work and increased social recognitions etc.

\section{Objectives}

- To analyze contributions of skill test on graduates' pre-employment, during-employment and post-employment stages?

- To explain overall contribution of the skill test to all stages both and to personal and external traits.

\section{Methods and Methodology}

This study applied quantitative methodology following survey to collect numerical description of relevant aspects of the sample graduates to investigate against the specific research questions. In the survey process, a specifically defined group of skills tested graduates were asked to answer a number of questions (Baker, 1994; Gupta \& Gupta, 2015). Of the various forms of survey, this study has applied a specialized survey that covers skill test and employment as the major subjects in the field of study (United Nations, 2007). The data collected from the selected representative sample through survey questionnaire were analyzed with the support of the SPSS 23 software. Descriptive statistics were generated on each item comprising the preference rating on each question denoting the Likert Scale from 1 to 5 . The ordinal scale measures the levels of agreement or disagreement with the stated questions. It assumed that the strength of preference or experience of the graduates could be measured from the continuum of strongly agree to strongly disagree. It also shows that preferences or attitudes can be measured. The descriptive statistics encompassing the Mean, Median and Mode scores and frequency distribution of each response were applied. The findings of this research can be generalized to the population who attended the skill test after completing their Level One vocational training from private training institutions.

1 The requirements are literate and having minimum 1 year work experience in related field or successful completion of 160 hours vocational training in related field or Six months' work experience in the relevant occupation/trade field and accreditation of certificate is non-gazette third (Technician).

Nepalese Journal of Development and Rural Studies, Volume 17 


\section{Population and Sampling Procedure}

A multi-staged random sampling method was applied to determine the sample population and sample number (Burton, 2007; Creswell, 2014) considering the sampling plans where sampling is carried out in stages using smaller and smaller sampling units in stage. At the first stage, there were a total of 55,311 short term vocational skill tested graduates for Level One in 2012 (NSTB, 2012) taken as the total population. At the second stage, out of the total population, the Central Development Region (i.e. the field of the study) had the highest number of the short term vocational skill tested graduates $(19,651)$, forming the theoretical population (NSTB, 2012). At the third stage, 1913 short term vocational skill tested graduates from the institutions which had the highest number of graduates were selected as the population of the study i.e. sample population. Finally, 305 sample graduates were selected for collecting the primary data which was generated with $95 \%$ confidence level by using the sample size determination formula (Krejcie \& Morgan, 1970).

\section{The Findings: Social Demographic Information of the Training Graduates}

This study highlighted sex, age, ethnicity, marital status, educational status, geographical origin, special condition, employment status and perception of trained graduates regarding the quality of training programs as demographic information. In the case of sex, majorities $(60 \%)$ of the graduates were women and the remaining 40 percent were men. The most (45.2\%) of the graduates 974 female $\& 63$ male) were from age group 25 to 30 years followed by the adolescent age group 16 to 25 years. The data shows that vocational training and skill test was more attractive for younger youths (16 to 30 years). In the case of ethnicity, majority (55\%) of the graduates belonged to the Janajati ethnic group and smallest minority (4\%) of the graduates belonged to Dalit ethnic group, while 20 percent and 18 percent of the graduates were from Chhetri/Thakuri and Brahmin ethnic groups respectively. The remaining 2 percent of the graduates were from the other ethnic groups such as the Muslims. The data indicates that the youths from every caste or ethnic group who were employed were from those who were equipped with vocational training and they were skill tested. In terms of marital status, out of total 295 responses, majorities 164 are married (110 female \& 54 male) and remaining 131 are unmarried (64 female \& 67 male). Similarly, largest numbers of graduates (51\%) passed secondary level and only 2 percent of the graduates have passed Bachelor and above. The remaining 22 percent and 20 percent have passed primary and higher secondary level respectively. Five percent graduates were found illiterate.

In terms of ecological region, majorities 59.7 percent graduates were from Hill region and 2.3 percent percent graduates from the Mountain region representing the highest and lowest number respectively. The remaining 38 percent of them were from the Terai region. The data indicated that a significant number of youths who completed the short term vocational training program and got the skill test belonged to the Hill and the Terai regions. In contrast, there was a minimal number of skill tested graduates from the Mountain region due to a small number of active population in the area, poor accessibility of technical education and vocational training program and difficult physical access to the Central Development Region. Besides, the physical condition of an individual and the socioeconomic and political condition of a country equally affect the life of an individual. This study also tried to categories some graduates into special conditions such as: differently-able, single women, war affected etc. The majority (98.7\%) of the graduates were normal or physically and mentally fit during 
their working and occupational life. The remaining 1.3 percent graduates, four in number, were under the 'special conditions' group: two graduates were found differently-able, one was a single woman and the other one was war affected. The data indicated that the smallest number of graduates were under 'special conditions might be due to poor enrollment opportunities, poor inclusiveness and physical difficulties.

In the case of occupational status, a great majority $(94.2 \%)$ of the graduates worked within the sectors in which they were trained, but the smallest minorities of them $(2 \%)$ were unemployed and the remaining 3.8 percent of the graduates worked in sectors other than those they were trained in. Finally, in the case of perception of the trained graduates towards the quality of the training, the Mode of their rating in descriptive preferences (i.e. Likert type scaling) was 3 which implied that the largest number of graduates were strongly satisfied with the quality of training they received. The Median of the distribution was also 3 (i.e. moderately satisfied), which means that 148 graduates were aligned towards agreeing the statement of being satisfied from the quality of the training received. Based on this result, it can be understood that 50 percent graduates were strongly satisfied and the remaining 50 percent graduates were for the 'partially satisfied' and 'satisfied' categories.

\section{Relation between the Skill Test and Employment}

The role of the skill test at the pre-employment, during-employment and post-employment stages have been explained separately (Table 1,2,3). Similarly, the descriptive analysis using the overall mean, median and mode, has been used to explain the overall contributions of the skill test to the above described employment stages. It also includes the disaggregated analysis of contributions of the skill test to the personal and external traits of the graduates at different employment stages.

Table 1. Role of the Skill Test at Pre-employment Stage (Ordinal Data-1)

\begin{tabular}{lllll}
\hline Role of Skills Test in Pre-employment Stages & N & Mean Rank & Median & Mode \\
\hline After skill tests, I see many job options & 300 & 4.2 & 4.00 & 4 \\
After skill tests, I had applied for many job options & 297 & 4.0 & 4.00 & 4 \\
After test, my self-encouragement to apply has increased & 299 & 4.3 & 4.00 & 4 \\
After skill test my training provider institute encourages me & 305 & 4.5 & 5.00 & 5 \\
to apply as many as possible even to foreign employment & & & \\
My level of confidence to face the job interview increased & 298 & 4.4 & 4.00 & 4 \\
My competency for employment market has been increased 298 & 4.3 & 4.00 & 4 \\
$\begin{array}{l}\text { I feel mounting trust among the employers and employees } \\
\text { After the skill test employers started to believe in my }\end{array}$ & 495 & 4.2 & 4.00 & 4 \\
technical knowledge, skills and inner personal ability & & 4.00 & 4
\end{tabular}

(Field Survey, 2016)

Referring to table 1, the Mode for the first statement (i.e. after skill tests I see many job options) was calculated to be 4, implying the largest number of graduates agreed that they saw many opportunities to start the employment after skill test. The Mean rank and the Median of the distribution were also 4.2 and 4 respectively (i.e. Agree), which means that nearly 50 percent of the graduates were aligned towards agreeing the first statement. Thus, 505 graduates were in the category of Strongly Disagree, Disagree and Neutral and the remaining 50 percent graduates in Strongly Agree and Agree categories. That is why, it can be concluded that the distribution was denser in the areas of 'Strongly 
Agree' and 'Agree', which implies that most of the graduates agreed that they saw many job options after having the skill test certification. Similarly, the Mode in the rest of the statements as listed in table was mostly 4 and 5 implying that the largest number of graduates agreed with the corresponding statements. The Mean rank and Median of distributions for the other statements were also 4 (i.e. Agree), which means nearly 50 percent of the graduates were aligned towards agreeing the respective statements. Thus, it can be understood that 50 percent of the graduates were on the side of Strongly Disagree, Disagree and Neutral; and the remaining 50 percent of them aligned to Strongly Agree and Agree. Then, it can be concluded that the distributions were denser in areas of Strongly Agree and Agree, which implies that most of the graduates agreed with each corresponding statement.

Table 2. Role of the Skill Test at During-employment Stage (Ordinal Data-2)

\begin{tabular}{lllll}
\hline Role of Skill Test in During- employment Stages & N & Mean Rank & Median & Mode \\
\hline My work efficiency has increased & 293 & 4.4 & 4.00 & 4 \\
Responses by coworkers during work has positively changed & 296 & 4.1 & 4.00 & 4 \\
Recognition by coworkers to me has increased & 297 & 4.2 & 4.00 & 4 \\
Self-awareness in work placesafety/security has increased & 297 & 4.3 & 4.00 & 4 \\
My self-awareness on decent work has been increased & 295 & 4.3 & 4.00 & 4 \\
My self-awareness on employment benefits has increased & 297 & 4.2 & 4.00 & 4 \\
My self-awareness on dutieshas been increased & 297 & 4.3 & 4.00 & 4 \\
My self-dignity has been increased & 297 & 4.3 & 4.00 & 4 \\
My capacity or specialization in my job has increased & 293 & 4.4 & 4.00 & 4 \\
I can work in team better than before & 297 & 4.4 & 4.00 & 4 \\
I can communicate better than before & 297 & 4.4 & 4.00 & 4 \\
My attitude towards vocational work has positively changed & 296 & 4.3 & 4.00 & 4 \\
\hline
\end{tabular}

(Field Survey, 2016)

The data in table 2 shows that the Mode for the first statement (i.e. my work efficiency has increased) was 4, implying that the largest number of graduates agreed that their work efficiency during the employment stage has increased due to the skill test. The Mean rank and Median of the distribution was also 4.4 and 4 respectively (i.e. Agree), which means fifty percent of the graduates were aligned towards agreeing the first statement. This further means that 146 graduates were in favor of Strongly Disagree, Disagree and Neutral; and the remaining 147 graduates on the Strongly Agree and Agree side. The denser distribution to Strongly Agree and Agree categories implies that most of the graduates agreed that their work efficiency during the employment stage has increased due to the skills tests. Similarly, regarding the rest of the statements too, the Mean, Median and Mode were 4, implying that the largest number of the graduates agreed with the corresponding statements.

Table 3. Role of the Skill Test at Post-employment Stage (Ordinal Data-3)

\begin{tabular}{lllll}
\hline Role of Skill Test at Post-employment Stage & N & Mean Rank & Median & Mode \\
\hline My career prosperity has increased & 294 & 4.3 & 4.00 & 5 \\
I upgraded my skill level more than before & 296 & 4.4 & 4.00 & 4 \\
My level of income has increased & 296 & 4.4 & 5.00 & 5 \\
My ability in self-recognition has increased & 298 & 4.3 & 4.00 & 4 \\
The number of job offers to me has increased & 298 & 4.2 & 4.00 & 4 \\
My social prestige has increased & 299 & 4.2 & 4.00 & 4
\end{tabular}


My purchasing power has increased

My family's access to better health care has increased

Access to education/trainings of my child have increased

I became able to buy the fixed assets

$\begin{array}{llll}301 & 4.4 & 4.00 & 4 \\ 298 & 4.0 & 4.00 & 4 \\ 298 & 4.0 & 4.00 & 4 \\ 288 & 3.5 & 4.00 & 4\end{array}$

(Field Survey, 2016)

According to table 3 the Mode for the first statement, 'My career prosperity has increased' was 5 , implying that largest number of graduates strongly agreed that their career prosperity increasedat the post- employment stage due to the skill test. The Mean rank and the Median of the distribution was 4.3 and 4 respectively (i.e. Agree), which means that 147 . Graduates aligned themselves towards agreeing the statement. It can be concluded that the distribution is denser to the areas of Strongly Agree and Agree, which implies that most of the graduates agreed that their career prosperity increased at the post- employment stage due to the skill test. Similarly, for the rest of the statements too, the Modes was 4 and 5 implying that most of the graduates agreed with the corresponding statements. The Mean and the Median of the distribution is also 4 (i.e. Agree), which means that fifty percent of the graduates aligned themselves towards agreeing the statement.

\section{Overall Contribution of the Skill Test to all Stages}

The overall Mean, Median and Mode related to the contribution of the skill test to the graduates at the three employment stages (pre-employment, during-employment and post-employment stages) through personal and external traits also have been explained (Table 4). To materialize the idea, the data were analyzed using the descriptive rating to all the responses viz. the Likert Scale.

Table 4. Contribution of the Skill Test to all the Three Stages

\begin{tabular}{llll}
\hline Overall Contribution of Skill Test & Mean & Median & Mode \\
\hline At pre- employment stage & 4.13 & 4.23 & 4.00 \\
At during-employment stage & 4.12 & 4.25 & 4.45 \\
At post- employment stage & 4.04 & 4.17 & 4.00 \\
\hline
\end{tabular}

(Field Survey, 2016)

The table 4 depicts that Mean Rank of overall contribution of the skill test in pre-employment stage of graduate was 4.14 implying that concentration of the responses was towards agree side. The Median for the same was 4.23 , implying that more than 50 percent of the responses were agreeing and strongly agreeing to the statements. Further, Mode was 4 , implying that maximum number of graduates agreed that there was overall contribution of the skill test in pre-employment stage of the graduates through their personal and external traits. Similarly, it was found that the Mean rank of the overall contribution of the skill test at the during-employment stage of the graduates was 4.12 which imply that concentration of the responses was on the Agree side. The Median for the same was 4.25, suggesting that more than 50 percent of responses were agreed and strongly agreed to the statements. Further, the Mode was 4.45, indicating that the largest number of graduates agreed that there was an overall contribution of the skill test to the during-employment stage of the graduates through their personal and external traits. It was also found that the Mean rank of overall contribution of the skill test at the post-employment stage of the graduates was 4.04 , implying that the concentration of the responses was on the Agree side. The Median for the same was 4.17, which implies that the more than 50 percent of the responses agreed and strongly agreed to the statements. Further, the Mode was 4.0, suggesting that 
the largest number of graduates agreed that there was an overall contribution of the skill test to the postemployment stage of the graduates through their personal and external traits.

\section{Overall Contribution of the Skill Test to Personal and External Traits}

The overall Mean, Median and Mode related to the contribution of the skill test to the graduates' employment through personal and external traits also have been explained (Table 5). To materialize the idea, the data were analyzed using the descriptive rating in all the responses viz. the Likert Scale.

Table 5. Overall Contribution of Skill Test in Personal and External Traits

\begin{tabular}{llll}
\hline Overall Contribution of the Skill Test & Mean & Median & Mode \\
\hline To personal traits & 4.29 & 4.50 & 4.20 \\
To external traits & 4.46 & 4.20 & 4.31 \\
\hline
\end{tabular}

(Field Survey, 2016)

The table 5 highlights that Mean rank, Median and Mode of overall responses about the contribution of the skill test to the employment through personal traits was 4.29, 4.50 and 4.20 respectively. This implies that the concentration of the responses was towards the Agree side. Furthermore, it can be seen that most of the graduates agreed that overall, there was contribution of the skill test to their employment through their personal traits. Similarly, the Mean rank, Median and Mode of overall responses about the contribution of the skill test in employment through the external traits was 4.46, 4.20 and 4.31 respectively. This implies that the concentration of the responses was towards Agree side. Furthermore, it can be understood that at the maximum of the graduates agreed that there was overall contribution of the skill test to the employment through their external traits. Besides, Pasa (2015) also reaveals that formulation and effective implementation of short term vocational skill testing system in local level is the need of today so that most of foreign labour migrants can grab semi-skilled employment opportunities through specific vocational skill tested certification.

\section{Theoretical Reflections}

The skill test significantly contributes personally and externally to the graduates' during preemployment stage. Conceptually, it was/is possible due to the occupational skill and ability of the graduates. While linking this concept with the human capital theory, it can be inferred that the skill tested graduates transformed into productive capital through their knowledge and skills. According to the Schultz, the basic components of the human capital formation are the ability (acquired through any means or innate), qualifications (acquired through formal or informal education) and skills (acquired through experience or training (Schultz, 1961; 1987). Here, because of the increasing level of occupational skills, the skill tested graduates enhance job opportunities in the national and international labour market. While doing so, they are also motivated by self (who got the vocational training and the skill test) and others (family, peer groups and training institutions) to apply for the jobs and start their careers. The skill test also increased the probability of self-recognition, further job offers, social prestige, and purchasing power, access to education and health and capability to buy some fixed assets. All those activities can also be analyzed owing to the human capability approach that has an intrinsic value for the well-being of people; an indirect role in influencing social change and influencing economic output (Sen, 1985; 2000).

Owing to the social structure and agency theory, the skill tested graduates, their family members and training providing institutions equally played the agency role for reforming the social 
and educational structures of the country in which school education system is producing unskilled and passive manpower. Social structure thus can reproduce individuals' actions and, their action to change the existing social structures. This shows that individuals' actions and agency relationships are the by-products of unproductive structures (Giddens, 1976). An agency relationship is one in which one or more persons engage with another person (the agent) to perform some service (Jensen, 1976). In our case, the individuals increase their self-encouragement to apply for more jobs, raised the level of confidence to face interviews. They experienced higher trust from their employers and stakeholders in their skills while attempting the job interviews.

From the viewpoint of the unlimited supply of labor theory, surplus labors from subsistence agriculture sectors are migrating from the urban sectors for becoming skilled manpower capable of work in non-agriculture sectors of the economy (Lekhi, 2008). According to this theory, a capitalist sector develops by utilizing labor from a non-capitalist backward or subsistence sector. The labor market sector demands more skillful labors to perform a certain vocational or occupational specific skill. Those skillful individuals who work in labor market can increase their skills from job experiences and they also accumulate their earnings. They can invest their earning in the village to run small enterprises. This might provide employment opportunities to the local people and uplift rural economy as a result.

During the employment stage, the skill tested graduates also gained recognition by co-workers, increased awareness about the work place safety and security, increased awareness about employment benefits as well as duties and responsibilities. The human capital formation theory has emphasized benefits of education in three different layers; self, society and nations (Psacharopoulos \& Woodhall, 1997). During the post employment stage, the skilled graduates not only are investing in health, education and for buying land property but also in non-agriculture sectors that lead to the expansion of employment opportunities by utilizing further labor form the subsistence sectors and ultimately to the economic development of the nation (Lekhi, 2008). In contrast, the skill test significantly differed from the marital status and geographical origin of the graduates. From the viewpoint of cultural structures, women are still facing a socio-cultural stigma. They are involving themselves in household chores rather than employment opportunities for playing economic roles. However, the government and I/ NGOs are working together for women empowerment. In such a situation, the guardians of the married women could not play agency role in which they embedded in social contexts which causally influence their original nature (Giddens, 1984). It is a time for rethinking on the minimal accessibility or urban centric vocational training and skill testing system by state mechanism. If the state mechanism analyzes vocational training, the skill testing system and employment practices from human capital formation perspectives it might benefit the nation itself. Because it is a process of investing in the youths by means of training, it raises their future income by increasing their life time earnings (Abeysinghe, 2012). While linking this issue with the structuration theory of Giddens, TEVT and Skill Testing Board can make an action on the basis of the ability or the capability of trainees and trained graduates as the structure and the agency are mutually dependent for forming or reforming structures which may affect future action. 


\section{Conclusion}

The research finding shows that the vocational skill training and test given to the graduates has significantly contributed to their employment. The skill test contributes personally and externally to the graduates' pre-employment stage by enhancing job opportunities. The graduates are getting benefits from the skill test at the beginning of their job carrier as they see many job options and receive intrinsic (by self) and extrinsic (by training) motivation to apply for the jobs. Further, it increases their self-encouragement to apply for more jobs, raises the level of confidence to face interviews and encourages more by the training providers. They are also experiencing higher trust of the employers and stakeholders in their skills while attempting the job interviews. The skill test contributes personally and externally to the graduates' during-employment stage by supporting them for the better job performances. The skill test is instrumental to the graduates during their job tenures as it facilitates them in areas like increased job efficiency, increased recognition by co-workers, increased awareness in workplace safety and security, increased awareness of the employment benefits as well as duties and responsibilities, increased self-dignity, increased team work capacity, increased communication skills and increased vocational work attitude.

The skill test contributes personally and externally to the graduates' post-employment stage by increasing better job prosperities. The skill test is influential even after their job because it facilitates them in areas like increased career prosperity, increased level of proficiency, increased level of income, increased self-recognition, increased further job offers, increased social prestige, increased purchasing power, increased access to education and health and increased capability to buy some fixed assets such as land property, motorbike, television and computer. The graduates are benefitting by the skill certification to foster the various personal traits like self-reorganization, self-encouragement, confidence, personal competency, work efficiency, self-awareness, self-dignity, team work, attitude towards work, income and purchasing power. Similarly, the skill test also contributes to foster the external traits of an individual like increased job options, increased trust among the employers, encouragement by the employers, recognition by other co-workers, level of income, increased career prospects, team work, increased social recognitions.

\section{Policy Implications}

For TVET Policy makers this study shows that skill test helps to make graduates to gain employment easily. That means more the investment in this sector better the creation of employment opportunity. In existing practice government has very less budget allocation for TVET sector rather it can be increased to make it more accessible and productive for the better employment and income opportunities within the country. The contribution of the vocational skill testing system is found significant to link the graduates to employment, through the enhancement of both personal and external traits. So, it is worthwhile to make a provision of the skill testing system in every vocational skill training program that is being implemented by various institutions. Likewise, for the TVET implementers this study proves that people who have acquired skills through informal and non-formal means can also be encouraged to take the skills test as a Recognition of Prior Learning (RPL) provision made by the existing CTEVT guideline.

Moreover, migrant workers who return with a good amount of earned capital together with vocational and entrepreneurial skills can also be part of the formal national certification system as study 
show the significant contribution to the employment of the graduates. This will further benefit them with better employment opportunities within the country, which will further contribute to the economic development of the nation. The participation of women and the benefits of certification to women is encouraging. Thus, it is worthful to increase engagement of women in TVET program irrespective of their caste, religion, ethnicity and origin. Finally, forTVET research professionals this study shows that skills test contributes not equally to the married and unmarried youth. Similarly, youths from different geographical locations are not getting equal benefit of the skill test. It can be an area for further research. In general, it is said that vocational education aims to produce a lower-medium level workforce and targets upon the literate and the illiterate (Greenan, Mingchang, Ramlee \& Lisa, 1998). However, this research showed that $53 \%$ of the graduates having secondary to bachelor level education were found to be enrolled in the vocational skills training and testing and also getting benefits from this.

\section{References}

Abeysinghe, A.M. (2012). Human capital formation: Trends and problems. Colombo: Corporate Management Division, University of Peradeniya.

Bajracharya, B. B. (2010). Technical education, vocational training and employment generation. Bhaktapur: CTEVT Research and Information Division.

Baker, T. L. (1994). Doing social research. NY: McGraw-Hill Inc.

Burton, L. (2007). Survey research: Choice instruments and sample. Baltimore: John Hopkins University Publication.

Council for Technical Education and Vocational Training. (1994). CTEVT profile Kathmandu: Author.

Council for Technical Education and Vocational Training.(2005). A study report on attraction of Nepalese youth in TVET program. Bhaktapur: Author

Council for Technical Education and Vocational Training.(2011). A study on the trends analysis of foreign employment and skill gap. Bhaktapur: Author.

Council for Technical Education and Vocational Training. (2011). A profile of national vocational providers, 2011. Bhaktapur: Author

Council for Technical Education and Vocational Training. (2012). Technical and vocational education and training policy. Bhaktapur: Author.

Council for Technical Education and Vocational Training. (2014). A milestone for the enhancement of technical and vocational education and training sector. TVET development journal, 14 (1). Bhaktapur: Author.

Creswell, J. W. (2014). Research design: Qualitative, quantitative and mix methods approaches (4th ed.). Los Angeles: University of Nebraska-Lincoln: Sage Publication.

Greenan, J., Mingchang, W., Ramlee, B. M. \& Lisa, B. N. (1998). Attitudes and motivations of vocational teachers regarding program improvement. Journal of Industrial Teacher Education, 35(3), 6-23.

Giddens, A. (1976). New rules of sociological method. London: Hutchinson.

Giddens, A. (1984). The constitution of society: Outline of the theory of structuration. Cambridge: Polity Press.

Gupta, C. B. \& Gupta, V. (2015). An Introduction to Statistical Methods (23rd ed.). Delhi: Vikas Publishing House.

Nepalese Journal of Development and Rural Studies, Volume 17 
Jensen, M. C. (1976). A theory of the firm: Managerial behavior, agency costs and ownership structure. Journal of Financial Economics. Rochester, USA: University of Rochester.

Kafle, A. P. (2007). Work force development in Nepal: Policies and practices. Kathmandu:Asian Development Bank Institute.

Krejcie, R. V. \& Morgan, D. W. (1970). Determining sample size for research activities. Educational and Psychological Measurement, 30, 607-610.

Lekhi, R. K. (2008). The economics of development and planning (11th ed.). New Delhi: Kalyani Publishers.

Lynch, R. L. (1997). Designing vocational and technical teacher education for the 21 st century: Implications from the reform literature. Ohio: The Ohio State University.

Nepal Living Standard Survey (NLSS). (2016). Nepal living standard survey report 2010-2011. Central Bureau of Statistics - National Planning Commission Secretariat: Government of Nepal.

Nepal Skill Testing Board (2012). A report on vocational training and skills test. Bhaktapur: Author.

Pasa, R. B. (2015). Short term vocational skill test in Nepalese contexts. Journal of Training and Development, 1, 54-61. Author. doi: https://doi.org/10.3126/jtd.v1i0.13091

Psacharopoulos, G. \& Woodhall, M. (1997). Education for development: An analysis of investment choice. NY: Oxford University Press.

Schaack, K \& Tippelt, R. (2000). Vocational training at the turn of the century. Frankfurt: Peter Lang.

Schultz, T. W. (1961). Investment in human capital [Presidential address delivered at the annual meeting of the American Economic Association, Saint Louis, MO. The American Economic Review, 51, 1-17.

Schultz, T. W. (1987). The formation of human capital. In G. Psacharopoulos. (Ed.), Economics of education (pp.1-13). NY: WB Publication.

Sen, A (1985). Commodities and capabilities. London: Oxford University Press

Sen, A. (2000). Development as freedom. London: Oxford University Press

Sharma, T. N. (1998). The role of technical education and vocational training in the broader perspective of Nepal's employment and training system (Unpublished Doctoral Thesis). University of Southern Illinois, Carbondale.

United Nation (2007). Resizing of house hold survey sample: Practical guideline. NY: Author. 